\title{
Effect of the provision of a low-nutritive feedstuff on the behavior of dairy heifers limit fed a high-concentrate ration
}

\author{
B. L. Kitts, ${ }^{*}$ I. J. H. Duncan, † B. W. McBride, † and T. J. DeVries ${ }^{\star 1}$ \\ *Department of Animal and Poultry Science, University of Guelph, Kemptville Campus, Kemptville, ON, Canada K0G 1J0 \\ †Department of Animal and Poultry Science, University of Guelph, ON, Canada N1G 2W1
}

\begin{abstract}
The objective of this study was to examine the behavioral and growth responses of dairy heifers when a low-nutritive feedstuff was provided with (either within or alongside) a limit-fed ration. Twenty-four Holstein dairy heifers $(187 \pm 11.3 \mathrm{~d}$ of age, $231.1 \pm 12.0 \mathrm{~kg})$, divided in groups of 4 , were exposed to each of 3 treatments in a replicated Latin square design with $28-\mathrm{d}$ periods. The treatment rations were (1) total mixed ration (TMR) in a limited amount (TMR-L), (2) TMR in a limited amount with straw $(1.8 \mathrm{~kg}$ of $\mathrm{DM} / \mathrm{d}$ per heifer) offered as a choice (TMR-SC), and (3) TMR in a limited amount with straw $(1.8 \mathrm{~kg}$ of $\mathrm{DM} / \mathrm{d}$ per heifer) mixed in (TMR-SM). The TMR was fed, once daily, at a restricted level (2.02\% of body weight) and contained (on a DM basis) 19.0\% alfalfa/grass haylage, $21 \%$ corn silage, $45 \%$ high moisture corn, and $15 \%$ protein supplement. Feeding behavior and unrewarded time at the feed bunk were recorded for the last $14 \mathrm{~d}$ of each period. Standing time was recorded for the last $7 \mathrm{~d}$ of each period. Rumination behavior was recorded twice weekly (during the fifth hour after feed delivery) in the last $14 \mathrm{~d}$ of each period. Body weight was recorded weekly and group DMI was recorded daily. Dry matter intake was lowest for the TMR treatment compared with the treatments with straw (5.7 vs. 7.3 $\mathrm{kg} / \mathrm{d}$ ). Heifer average daily gain tended to be lower on the TMR-SM treatment compared with the TMR-L and TMR-SC treatments ( 0.78 vs. $0.94 \mathrm{~kg} / \mathrm{d})$. Feed efficiency (DMI/ADG) was improved on the TMR-L (6.3) compared with TMR-SC (7.8) and TMR-SM (9.9) treatments. Daily feeding time differed between the TMR-L (76.1 min/d), TMR-SC (206.9 min/d), and TMR-SM (279.2 min/d) treatments. Unrewarded feeding time at the feed bunk differed between the TMR-L (38 min/d) compared with the TMR-SC $(10.9 \mathrm{~min} / \mathrm{d})$ and TMR-SM $(1.7 \mathrm{~min} / \mathrm{d})$ treatments. Inactive standing time differed among treatments, with TMR-L be-
\end{abstract}

Received August 27, 2010.

Accepted November 3, 2010.

${ }^{1}$ Corresponding author: tdevries@uoguelph.ca ing the highest compared with TMR-SC and TMR-SM (556.4 vs. 409.9 vs. $340.1 \mathrm{~min} / \mathrm{d}$ ). There tended to be fewer heifers ruminating on the TMR-L compared with TMR-SM (14.0 vs. 21.9\%). The results suggest that provision of straw as a choice alongside a limit-fed ration will allow heifer growth rates to be met, as well as provide a suitable foraging source that heifers can use to satisfy their natural feeding behavior patterns.

Key words: dairy heifer, feeding behavior, limit feeding

\section{INTRODUCTION}

The costs associated with replacement dairy heifers are second only to the feed costs of lactating cows, representing 15 to $20 \%$ of total milk production costs on a dairy farm (Heinrichs, 1993). As replacement heifers provide no immediate financial benefits to producers until the onset of lactation, it is important to minimize rearing costs. However, this cannot be done at the expense of production potential, health, or welfare, as healthy and potentially productive heifers are needed to replace close to $40 \%$ of the lactating herd each year (Quaiffe, 2002).

Growing dairy heifers are typically fed a high-forage, low-energy ration to meet their energy and nutrient requirements and thus control their ADG. Researchers have recently investigated how energy and nutrient intakes can be controlled by limit feeding a more nutrient-dense ration (Hoffman et al., 2007; Moody et al., 2007; Zanton and Heinrichs, 2007). Limit feeding allows for growth rates to be controlled, while potentially reducing feed costs, decreasing fecal excretion, and increasing feed efficiency (Hoffman et al., 2007; Moody et al., 2007; Lascano et al., 2009).

Despite the benefits of limit feeding, this feeding strategy poses potential behavioral concerns for dairy heifers. Hoffman et al. (2007) observed that limit feeding reduced eating and lying time, resulting in heifers standing for more time without eating, which may increase the risk of hoof pathologies (Cook et al., 2004; Vanegas et al., 2006). These researchers also found that limit feeding increased vocalization levels in heif- 
ers (Hoffman et al., 2007), as well as increased the amount of aggressive "reaching" to acquire feed (Hoffman, 2007). Limit feeding dairy cattle also has been associated with increased levels of oral stereotypies, including tongue rolling, constant head nodding, and bar biting or licking (Redbo et al., 1996; Redbo and Nordblad, 1997; Lindström and Redbo, 2000). These changes in behavior may be attributed to hunger and frustration as a result of lack of satiety (Savory et al., 1993), not only due to limited rumen fill, but also due to limited oral manipulation of feed (Lindström and Redbo, 2000). Consumption of feed within $2 \mathrm{~h}$ of feed delivery, as seen in limit-fed heifers (Hoffman et al., 2007), is much different from the average feeding time of 3 to $5 \mathrm{~h}$ for heifers fed a high-forage ration ad libitum (Greter et al., 2008; DeVries and von Keyserlingk, 2009a) and even more different from the 4 to $9 \mathrm{~h}$ that dairy cattle, under natural grazing conditions, would engage in foraging behavior throughout the day (Hafez and Bouissou, 1975).

To date, little research has been done on reducing these potentially negative behavioral effects of limit feeding in dairy heifers. For gestating sows, which are often limit-fed, the most common method identified to reduce negative behaviors and satisfy foraging needs is to accompany their restricted diet with a low-nutritive feedstuff, such as straw (Spoolder et al., 1995; Whittaker et al., 1998; D'Eath et al., 2009). Greter et al. (2008) recently demonstrated that straw could be added to an ad libitum-fed TMR for growing dairy heifers to increase feeding time. It has yet to be determined, however, if the increased feed efficiency gained and the ability to control growth rate with a limit-fed ration can be maintained when a low-nutritive feedstuff (such as straw) is also offered. Therefore, the objective of this study was to examine the behavioral and growth effects on dairy heifers when a low-nutritive feedstuff was provided with (either within or alongside) a high-concentrate ration fed in a limited amount. We hypothesized that the addition of straw to a limit-fed ration would allow heifers to satisfy their natural foraging behavior without significantly affecting their feed efficiency and growth.

\section{MATERIALS AND METHODS}

\section{Animals and Housing}

Twenty-four Holstein dairy heifers were used in this study and were acquired on loan from a local commercial dairy operation. Upon arrival, heifers were given a broad-spectrum antibiotic (Draxxin, tulathromycin, Pfizer Animal Health, Kirkland, QB, Canada) to prevent potential sickness due to transport and mixing stresses (Stanton et al., 2010). The heifers were given a 14-d adaptation period before exposure to experimental treatments. The heifers were (mean \pm SD) $187 \pm 11.3$ $\mathrm{d}$ old, weighed $231.15 \pm 12.0 \mathrm{~kg}$, and measured 112.1 $\pm 2.8 \mathrm{~cm}$ tall at the withers at the beginning of the experiment. Heifers weighed $314.2 \pm 16.4 \mathrm{~kg}$ and were $123.2 \pm 2.8 \mathrm{~cm}$ tall at the withers at the end of the experiment. Heifers were housed in groups of 4 in 6 pens. The pens were located in a naturally ventilated cold barn at the University of Guelph, Kemptville Campus (Kemptville, ON, Canada), and were managed according to the guidelines set by the Canadian Council on Animal Care (1993). Use of heifers was approved by the University of Guelph's Animal Care Committee (AUP\#09R022). The experiment was conducted between May and August 2009. The pens consisted of an indoor sand-bedded pack area $(3.6 \mathrm{~m}$ wide $\times 10.9 \mathrm{~m}$ deep) and an outdoor concrete run $(3.6 \mathrm{~m} \times 16.4 \mathrm{~m})$. Sand bedding was cleaned out and replenished every 7 to $10 \mathrm{~d}$ throughout the experiment. Feed bunks were located along the front of each indoor pack area and measured $2.70 \mathrm{~m}$ in length (split into $21.35-\mathrm{m}$ sections), allowing a total of $0.68 \mathrm{~m}$ of bunk space/heifer. Orts were cleaned out of feed bunks at $1030 \mathrm{~h}$ each day, with new feed delivered once daily at $1130 \mathrm{~h}$. Water was available ad libitum to the heifers through a water bowl in each pen. Heifers also were given ad libitum access to trace mineral salt blocks (Windsor TM Stock Salt, The Canadian Salt Co. Ltd., Pointe-Claire, QB, Canada).

\section{Experimental Design and Rations}

The number of pens required per treatment was determined through power analysis (Morris, 1999) for primary response variables, including DMI, feeding behavior, and ADG. Estimates of variation for these variables were based on previously reported values (Kertz and Chester-Jones, 2004; Hoffman et al., 2007; Greter et al., 2008). Heifers were divided into 6 groups of 4 that were balanced for age, weight, and height. Heifers had previously been fed a TMR, and over the 14-d adaptation period, were gradually accustomed to increased concentrate in their TMR. From d 1 to 7 of that period, heifers were fed a ration consisting of (on a DM basis) $38 \%$ corn silage, $34 \%$ grass/alfalfa haylage, $16 \%$ high-moisture corn, and $12 \%$ protein supplement. From $\mathrm{d} 8$ to 14 , they were fed (on a DM basis) a ration consisting of $32 \%$ corn silage, $26 \%$ haylage, $27 \%$ highmoisture corn, and $15 \%$ protein supplement. Both rations during the adaptation period were fed ad libitum. After this period, heifers were switched to a limit-fed TMR (Table 1). This TMR was formulated and fed at a restricted level $(2.02 \%$ of $\mathrm{BW})$ to meet the nutrient 
Table 1. Ingredient composition of the TMR (\%, DM basis) fed to growing dairy heifers ${ }^{1}$

\begin{tabular}{lc}
\hline Ingredient, \% & TMR \\
\hline Corn silage & 21 \\
Alfalfa/grass haylage & 19 \\
High-moisture corn $^{2}$ & 45 \\
Protein supplement $^{3}$ & 15 \\
\hline
\end{tabular}

${ }^{1}$ TMR used for all 3 treatment rations.

${ }^{2}$ Chemical composition of high-moisture corn (DM basis) was $8.1 \pm$ $0.3 \% \mathrm{CP}, 4.2 \pm 0.6 \% \mathrm{ADF}$, and $12.4 \pm 1.4 \% \mathrm{NDF}$.

${ }^{3}$ Supplied by Ritchie Feed \& Seed Inc. (Ottawa, ON, Canada), containing (on as-is basis): $30.3 \%$ soybean meal, $24.2 \%$ Tri-Pro Gold (TriCounty Protein Corp., Winchester, ON, Canada), 16.5\% corn gluten meal, $11.0 \%$ canola meal, $5.9 \%$ ground limestone, $5.8 \%$ trace mineral/ vitamin premix, $4.1 \%$ sodium bicarbonate, $2.2 \%$ cobaltized-iodized salt.

requirements for a nonbred Holstein heifer growing at $0.9 \mathrm{~kg} / \mathrm{d}$ (NRC, 2001).

Following the adaptation period, groups of heifers were exposed to each of 3 dietary treatments, in $28-\mathrm{d}$ periods, using a replicated $3 \times 3$ Latin square design. The treatments were (1) limit-fed TMR (TMR-L), (2) limit-fed TMR with access to wheat straw on the side (TMR-SC), and (3) limit-fed TMR with wheat straw mixed in the ration (TMR-SM). For the 2 straw treatments, wheat straw constituted approximately $30 \%$ (on a DM basis) of offered feed. Each 28-d treatment period consisted of a 14-d adaptation period (to allow heifers to acclimate to the new treatment) followed by a $14-\mathrm{d}$ data collection period.

Each day, dietary components were mixed in a TMR mixer wagon (Reel-Auggie model 3250, Kuhn Knight Inc., Brodhead, WI). The appropriate amount of TMR was manually weighed out for each pen. For the TMRSM treatment, the TMR and wheat straw were thoroughly mixed on the cement floor in front of the each feed bunk for 10 min using a pitchfork. After mixing was complete, feed was placed in the feed bunk. For TMR-SC treatment, the appropriate amount of wheat straw was placed in half of the feed bunk, with the TMR placed in the other half. The total amount of feed offered to each pen was adjusted, according to average pen heifer BW, every 2 wk.

\section{Feed Intake and Growth Measurements}

Group intakes were recorded daily throughout the study by weighing the amount of feed offered and amount of feed refused (if any). This data was used to calculate daily DMI $(\mathrm{kg} / \mathrm{d})$ on a pen basis. Heifers were weighed and measured for the same 2 consecutive days each week to measure weight gain (ADG). Feed efficiency was calculated as kilograms of DMI per kilogram of gain.

\section{Behavioral Measurements}

Feeding and competitive behavior were monitored using time-lapse video continuously for the last $14 \mathrm{~d}$ of each treatment period. Heifers were recorded using 1 video camera (WV-BP330, Panasonic, Osaka, Japan) per pen, a time-lapse video cassette recorder (Panasonic AG-6740) and a video multiplexer (Panasonic WJ-FS 616). Video cameras were mounted $3.2 \mathrm{~m}$ above each of the 6 feed bunks. Red lights $(100 \mathrm{~W})$, mounted adjacent to the cameras, were used to facilitate recording at night. Individual heifers were identified within each pen by their unique patterns. Digital photographs were taken of each animal's head, as well as a dorsal view of the back. These photos were used during video analysis to identify individuals within each pen.

The amount of time spent feeding during each 14-d recording period was scored for individual heifers using instantaneous scan sampling every $10 \mathrm{~min}$. For each scan, feeding was defined when a heifer had her head completely past the feed rail and over the feed. To validate this scanning method, we compared continuous video observations for each heifer, with 10-min scan samples over a 24 - $h$ period. The correlation was $r=0.95$; thus, this method proved adequate as demonstrated by Endres et al. (2005) for mature dairy cattle. Therefore, total minutes spent feeding was calculated by multiplying the number of scans by 10 . Total time spent feeding was then calculated for each heifer for each day of the 14-d recording period. To identify changes in diurnal feeding patterns between treatments, these scans were used to calculate the percentage of heifers feeding at the feed bunk over a $24-\mathrm{h}$ period. Based on these diurnal feeding patterns, the time period when feeding activity was greatest was identified $(1.5 \mathrm{~h}$ following feed delivery when all of the limit-fed TMR was consumed), and the amount of time spent feeding during the period was calculated. Unrewarded feeding time (presence at the feed bunk when no feed was present) also was measured using 10-min scans. For each scan, unrewarded feeding was defined when a heifer had her head completely past the feed rail and over an empty feed bunk. To validate this scanning method, we compared continuous video observations, for each heifer, with 10-min scan samples over a 24-h period; the correlation was $r=0.99$. Total daily unrewarded feeding time was calculated for each day of the 14-d recording periods by multiplying the number of scans by 10 .

Feeding competition, recorded as displacements from the feed bunk while feeding, was measured on d 23, 25 , and 28 of each treatment period. A displacement was marked when a butt or a push from the actor (instigator) resulted in the complete withdrawal of the reactor's head from beneath the feed rail (DeVries et 
al., 2004). These observations were used to calculate the number of times each heifer was displaced from the feed bunk each day.

Rumination behavior was measured on d 16, 18, 23, and 25 during each treatment period. On these days, rumination behavior was recorded by live scan sampling of each pen every minute for 60 min starting at $1600 \mathrm{~h}$. From this data, the average percentage of heifers ruminating during this time period within each pen was calculated. Based on the findings of DeVries et al. (2009), observing the percentage of heifers ruminating over 60 individual minutes should provide an accurate estimate of the mean and allow for the detection of possible differences in rumination activity between treatments.

Standing and lying behavior were recorded during the last $7 \mathrm{~d}$ of each treatment period. Daily lying times of individual heifers were collected using electronic data loggers (HOBO Pendant G Data Logger, Onset Computer Corp., Pocasset, MA; Ledgerwood et al., 2010). These devices were placed on the hind leg of each heifer using veterinary bandaging (Vetrap bandaging tape, 3M, St. Paul, MN), and the devices measured the orientation of the leg at 1-min intervals. This data was summarized to calculate the average daily standing and lying time $(\mathrm{min} / \mathrm{d})$, as well as the frequency of lying bouts (number/d). These data were used to determine inactive standing time (standing while not feeding) by calculating the difference between feeding time and standing time.

\section{Feed Sampling and Analysis}

Representative grab samples of the TMR, TMR-SM, wheat straw, and orts (if any) were taken for DM and chemical analysis during the last $14 \mathrm{~d}$ (recording weeks) of each treatment period. Samples of the dietary components also were taken for DM and chemical analysis once during these recording weeks. Duplicate samples of forage components were taken once a week during the last $14 \mathrm{~d}$ of each treatment period for particle size separation. Grab samples of TMR, TMR-SM, and wheat straw also were collected for particle size separation at the time of feed delivery (i.e., after feed mixing was finished) each day during the last $14 \mathrm{~d}$ of each treatment period. Orts (if any) samples also were collected for DM and particle size separation from each feed bunk at the end of each recording day when the feed bunks were cleaned out. All samples were immediately frozen at $-20^{\circ} \mathrm{C}$ until they were analyzed.

Samples for particle size separation were thawed at a later date and separated using a 3-screen $(19,8,1.18$ $\mathrm{mm}$ ) Penn State particle separator (Kononoff et al., 2003). This separated the samples into 4 fractions: long $(>19 \mathrm{~mm})$, medium $(<19,>8 \mathrm{~mm})$, short $(<8$, $>1.18 \mathrm{~mm})$, and fine $(<1.18 \mathrm{~mm})$ particles. After separation, the DM of each separated fraction was determined by forced-air drying at $55^{\circ} \mathrm{C}$ for $48 \mathrm{~h}$. The physical effectiveness factor was determined as the DM proportion of particles retained by the top 2 sieves of the Penn State Particle Separator (Yang and Beauchemin, 2006a). The physically effective NDF was calculated by multiplying the NDF content of the feed by the physical effectiveness factor.

Samples taken for DM and chemical analysis were oven-dried at $55^{\circ} \mathrm{C}$ for $48 \mathrm{~h}$ and then ground to pass through a 1-mm screen (Wiley mill, Arthur H. Thomas Co., Philadelphia, PA). These samples were then sent to Cumberland Valley Analytical Services, Inc. (Maugansville, $\mathrm{MD})$ for analysis of $\mathrm{DM}\left(135^{\circ} \mathrm{C}\right.$; AOAC, 2000 ; method 930.15), ADF (AOAC, 2000; method 973.18), NDF with heat-stable $\alpha$-amylase and sodium sulfite (Van Soest et al., 1991), and CP $(\mathrm{N} \times 6.25)$ (AOAC, 2000; method 990.03; Leco FP-528 nitrogen analyzer, Leco, St. Joseph, MI).

\section{Calculations and Statistical Analysis}

Sorting was calculated as the actual DMI of each Penn State Particle Separator fraction expressed as a percentage of the predicted DMI of that fraction (Leonardi and Armentano, 2003). The actual intake of each individual fraction was determined as the difference between the DM amount of each fraction in the offered feed and that in the refused feed. The predicted intake for each individual fraction was determined by the DMI of the total ration multiplied by the DM percentage of that fraction in the offered ration. Values equal to $100 \%$ indicate no sorting, $<100 \%$ indicate selective refusals (sorting against), and $>100 \%$ indicate preferential consumption (sorting for).

For analyses of treatment effects, the pen was considered the experimental unit. Data for intakes, growth (ADG), feed efficiency, feeding, lying or standing, competitive behavior, and rumination were averaged for each pen by treatment period. Pen variance in ADG was calculated by averaging, per pen, the absolute difference between individual heifer ADG and pen mean ADG. Data for feed bunk attendance (percentage of heifers feeding) was summarized by hour for each pen, for each treatment period.

Preliminary screening of the data revealed that all dependent variables were normally distributed. To test for differences among treatments, all data were analyzed using the MIXED procedure (SAS Institute, 2003). The model included the fixed effects of period, square, and treatment, the random effect of pen within square, and the residual error. Interactions of the period and square 
Table 2. Nutrient composition and particle size distribution of the TMR-L and TMR-SM treatment rations fed to growing dairy heifers $(\text { mean } \pm \mathrm{SD} ; \mathrm{DM} \text { basis })^{1}$

\begin{tabular}{lcc}
\hline Item & TMR-L & TMR-SM \\
\hline Chemical composition $^{2}$ & & \\
DM, \% & $61.6 \pm 0.8$ & $69.0 \pm 0.3$ \\
CP, \% & $15.6 \pm 0.6$ & $12.8 \pm 0.6$ \\
ADF, \% & $19.5 \pm 0.6$ & $31.9 \pm 1.6$ \\
NDF, \% & $28.6 \pm 0.5$ & $42.8 \pm 1.8$ \\
NFC, ${ }^{3} \%$ & $45.1 \pm 0.5$ & $33.1 \pm 1.1$ \\
OM, \% & $91.8 \pm 0.4$ & $90.2 \pm 0.9$ \\
Calculated nutrients $^{4}$ & $72.1 \pm 0.5$ & $62.3 \pm 0.7$ \\
TDN $^{5}$ & $2.6 \pm 0.02$ & $2.3 \pm 0.01$ \\
ME, Mcal/kg $_{\text {NE }}$, Mcal/kg & $1.1 \pm 0.01$ & $0.8 \pm 0.02$ \\
NE & Mcal/kg, $\mathrm{kg}$ & $1.4 \pm 0.02$ \\
Particle size, $\%$ & $1.7 \pm 0.02$ & \\
Long & $3.8 \pm 1.6$ & $27.4 \pm 12.0$ \\
Medium & $46.6 \pm 4.0$ & $31.5 \pm 6.2$ \\
Short & $38.0 \pm 3.5$ & $31.7 \pm 7.4$ \\
Fine & $11.7 \pm 1.8$ & $8.2 \pm 2.4$ \\
\hline
\end{tabular}

${ }^{1} \mathrm{TMR}=21 \%$ corn silage, $19 \%$ alfalfa/grass silage, $45 \%$ high-moisture corn, and $15 \%$ protein supplement; TMR-L = limit-fed TMR; TMR$\mathrm{SM}=\mathrm{TMR}$ and straw mixed within.

${ }^{2}$ Values were obtained from chemical analysis of feed samples; $\mathrm{OM}=$ $100-\%$ ash.

${ }^{3} \mathrm{NFC}=100-(\% \mathrm{NDF}+\% \mathrm{CP}+\%$ ether extract $+\%$ ash $)$.

${ }^{4}$ Calculated according to NRC (2001) equations.

${ }^{5}$ Total digestible nutrients (calculated from ingredients).

${ }^{6}$ Particle size determined with a Penn State Particle Separator, which has 19-mm (long), 8-mm (medium), and 1.18-mm screens (short) and a pan (fine).

with treatment were tested in the model and were not significant; therefore, these are not further reported. All values reported are least squares means. The TukeyKramer method was used to adjust the probability differences between least squares means. Significance was declared as $P \leq 0.05$ and trends were reported if 0.05 $<P \leq 0.10$.
To test for the effect of treatment for diurnal feeding patterns, the data were analyzed using the MIXED procedure (SAS Institute, 2003), treating hour as a repeated measure. The model included the fixed effects of treatment, hour, square, and the random effect of pen within treatment. The covariance structure was autoregressive, according to the best-fit Schwarz's Bayesian information criterion. All values were reported as least squares means.

\section{RESULTS}

\section{Dietary Composition}

Nutrient composition of the TMR-L and TMR-SM treatment rations are reported in Table 2. Nutrient composition of the forages is presented in Table 3. Because of the addition of straw to the TMR, the TMR$\mathrm{SM}$ treatment ration was lower in DM, CP, NFC, OM, TDN, ME, $\mathrm{NE}_{\mathrm{G}}$, and $\mathrm{NE}_{\mathrm{M}}$, and higher in $\mathrm{ADF}$ and NDF. With the addition of straw, the percentage of long particles increased and the percentage of medium, short, and fine particles decreased in the TMR-SM treatment ration compared with the TMR-L (Table $2)$.

\section{Behavior}

Feeding time differed among all treatments, being lowest while heifers were on the TMR-L treatment and highest when on the TMR-SM treatment (Table 4). This difference in feed activity is seen in Figure 1, with a clear difference in the percentage of heifers present at the feed bunk over the course of the day $(\mathrm{SE}=0.9, P$ $<0.001)$. In the analysis of diurnal feeding activity, a treatment $\times$ hour interaction $(P<0.001)$ was detected.

Table 3. Chemical composition and particle size distribution of the forages (mean \pm SD; DM basis)

\begin{tabular}{lcrr}
\hline Item & Alfalfa/grass haylage & Corn silage & Straw \\
\hline Chemical composition $^{1}$ & & & \\
DM, \% & $50.8 \pm 2.0$ & $44.7 \pm 1.6$ & $90.3 \pm 0.7$ \\
CP, \% & $16.9 \pm 0.2$ & $7.7 \pm 0.4$ & $6.7 \pm 1.1$ \\
ADF, \% & $46.8 \pm 1.6$ & $18.2 \pm 1.0$ & $55.7 \pm 1.4$ \\
NDF, \% & $54.5 \pm 1.8$ & $32.3 \pm 1.9$ & $74.3 \pm 1.3$ \\
NFC, $\%$ & $14.4 \pm 2.2$ & $53.9 \pm 2.0$ & $7.6 \pm 2.1$ \\
OM, \% & $86.0 \pm 0.6$ & $97.0 \pm 0.1$ & $88.0 \pm 1.6$ \\
Particle size ${ }^{3} \%$ & $26.4 \pm 4.5$ & $4.3 \pm 1.1$ & $69.7 \pm 10.4$ \\
Long & $43.0 \pm 3.8$ & $55.7 \pm 3.4$ & $19.0 \pm 5.3$ \\
Medium & $24.2 \pm 2.0$ & $33.7 \pm 2.2$ & $9.9 \pm 6.0$ \\
Short & $6.4 \pm 2.2$ & $6.3 \pm 1.1$ & $1.5 \pm 1.1$ \\
Fine & & & \\
\hline
\end{tabular}

${ }^{1}$ Values were obtained from chemical analysis of feed component samples.

${ }^{2} \mathrm{NFC}=100-(\% \mathrm{NDF}+\% \mathrm{CP}+\%$ ether extract $+\%$ ash $)$.

${ }^{3}$ Particle size determined by Penn State Particle Separator, which has 19-mm (long), 8-mm (medium), and 1.18-mm screens (short) and a pan (fine). 
Table 4. Effect of treatment rations on behavioral measures of growing dairy heifers ${ }^{1}$

\begin{tabular}{|c|c|c|c|c|c|}
\hline \multirow[b]{2}{*}{ Item } & \multicolumn{3}{|c|}{ Treatment $^{2}$} & \multirow[b]{2}{*}{$\mathrm{SE}$} & \multirow[b]{2}{*}{$P$-value } \\
\hline & TMR-L & TMR-SC & TMR-SM & & \\
\hline Feeding time, $\min / \mathrm{d}$ & $72.9^{\mathrm{a}}$ & $203.2^{\mathrm{b}}$ & $285.2^{\mathrm{c}}$ & 5.4 & $<0.001$ \\
\hline Peak feeding time, ${ }^{3} \mathrm{~min} / \mathrm{d}$ & $72.3^{\mathrm{a}}$ & $81.0^{\mathrm{b}}$ & $86.6^{\mathrm{c}}$ & 0.1 & 0.001 \\
\hline Unrewarded feeding time, $\mathrm{min} / \mathrm{d}$ & $38.0^{\mathrm{a}}$ & $10.9^{\mathrm{b}}$ & $1.7^{\mathrm{b}}$ & 4.8 & 0.01 \\
\hline Displacements, no./d & $4.7^{\mathrm{a}}$ & $18.2^{\mathrm{b}}$ & $27.4^{\mathrm{c}}$ & 1.8 & 0.001 \\
\hline Peak displacements, ${ }^{3}$ no. $/ \mathrm{d}$ & $4.6^{\mathrm{b}}$ & $5.8^{\mathrm{b}}$ & $10.9^{\mathrm{a}}$ & 1.2 & 0.04 \\
\hline Lying time, $\min / \mathrm{d}$ & 807.1 & 825.1 & 823.0 & 0.08 & 0.1 \\
\hline Lying bouts, no./d & 10.5 & 10.4 & 10.3 & 0.3 & 0.7 \\
\hline Inactive standing time, $\mathrm{min} / \mathrm{d}$ & $556.4^{\mathrm{a}}$ & $409.9^{\mathrm{b}}$ & $340.1^{\mathrm{c}}$ & 6.4 & $<0.001$ \\
\hline Rumination, $\%$ of heifers & $14.0^{*}$ & 17.5 & $21.9^{*}$ & 2.0 & 0.1 \\
\hline
\end{tabular}

${ }^{\mathrm{a}-\mathrm{c}}$ Values within rows without a common superscript differ $(P<0.05)$.

${ }^{1}$ Data for total and peak feeding time, unrewarded time at the feed bunk, and total and peak displacements are averaged over $14 \mathrm{~d}$ across each period treatment. Data for lying time, bouts, and inactive standing time are averaged over the last $7 \mathrm{~d}$ across each period treatment. Data for rumination was averaged for $\mathrm{d} 16,18,23$, and 25 across each period treatment.

${ }^{2} \mathrm{TMR}=21 \%$ corn silage, $19 \%$ alfalfa/grass silage, $45 \%$ high-moisture corn, and $15 \%$ protein supplement; TMR-L = limit-fed TMR; TMR-SC = TMR and straw offered on the side; TMR-SM = TMR and straw mixed within

${ }^{3}$ Peak feeding activity period $=1.5$ - $\mathrm{h}$ period immediately following feed delivery.

*Values within row tended to differ $(0.05<P<0.1)$.

This interaction reflects the similar percentage of heifers across treatments at the feed bunk during the 1.5-h period of feeding activity following feed delivery, with a greater percentage of heifers at the feed bunk for the straw treatments in the later hours of the day. Within that 1.5-h period, all of the TMR was consumed on the TMR-L and the TMR-SC treatments (Figure 1 and 2) in a similar time span (72.3 vs. $79.9 \mathrm{~min} / \mathrm{d}$ ). The amount of time spent feeding during the $1.5 \mathrm{~h}$ after feed delivery was longer on the TMR-SC compared with the TMR-L treatment (Table 4), this was due to the fact that on the TMR-SC treatment, once the TMR was consumed, heifers started immediately to consume the straw provided as a choice (Figure 2) and spent $123 \mathrm{~min} / \mathrm{d}$ consuming the straw. Feeding time on the TMR-SM treatment was longest during that peak period (Table 4), and this feeding activity continued for several hours following that period (Figure 1). Unrewarded time at the feed bunk was greatest for the TMR-L treatment, with no differences in unrewarded time between the 2 straw treatments (Table 4 ).

The frequency of daily displacements differed between all treatments, being lowest for the TMR-L treatment and greatest for the TMR-SM treatment. Interestingly, during the period of peak feeding activity, the frequency of displacements did not differ between the TMR-L and TMR-SC treatments. The frequency of displacements was, however, greater during this time period on the TMR-SM treatment. Daily lying time or frequency of lying bouts did not differ between treatments. The length of inactive standing time did, however, differ between all treatments. Inactive standing was shortest for the TMR-SM treatment and longest for the TMR-L treatment. In the fifth hour following the daily delivery of feed, there tended $(P=0.1)$ to be fewer heifers ruminating on the TMR-L treatment compared with the TMR-SM treatment.

No sorting for the TMR-L treatment occurred as heifers consumed all of the feed with no leftovers. With the TMR-SM treatment, heifers sorted against the long particles $(97 \%$; $\mathrm{SE}=0.6 ; P=0.001)$, and sorted for medium (100.6\%; $\mathrm{SE}=0.2 ; P=0.002)$, short $(101 \%$; $\mathrm{SE}=0.2 ; P=0.001)$, and fine $(101 \% ; \mathrm{SE}=0.2 ; P<$ $0.001)$ particles. In the TMR-SC treatment, heifers consumed all of the TMR; however, they sorted the straw for the long particles $(102 \% ; \mathrm{SE}=0.7 ; P=0.001)$, did not sort for or against the medium particles, sorted against the short particles $(93 \% ; \mathrm{SE}=1.8 ; P=0.006)$ and did not sort for or against the fine particles.

\section{Intake and Growth}

Given that the TMR was fed at a restricted level, DMI was lowest in the TMR-L treatment (Table 5). Within the straw treatments, DMI was greater for the TMR-SM treatment compared with that of the TMRSC treatment. Similar intake patterns were found for the intake of ADF and NDF. Intake of physically effective NDF differed among treatments, being lowest on the TMR-L treatment and greatest on TMR-SC treatment. Consumption of total digestible nutrients was lowest on the TMR-L treatment but increased with the addition of straw to the ration. No difference in $\mathrm{NE}_{\mathrm{G}}$ was found between the TMR-L treatment and the 2 straw treat- 


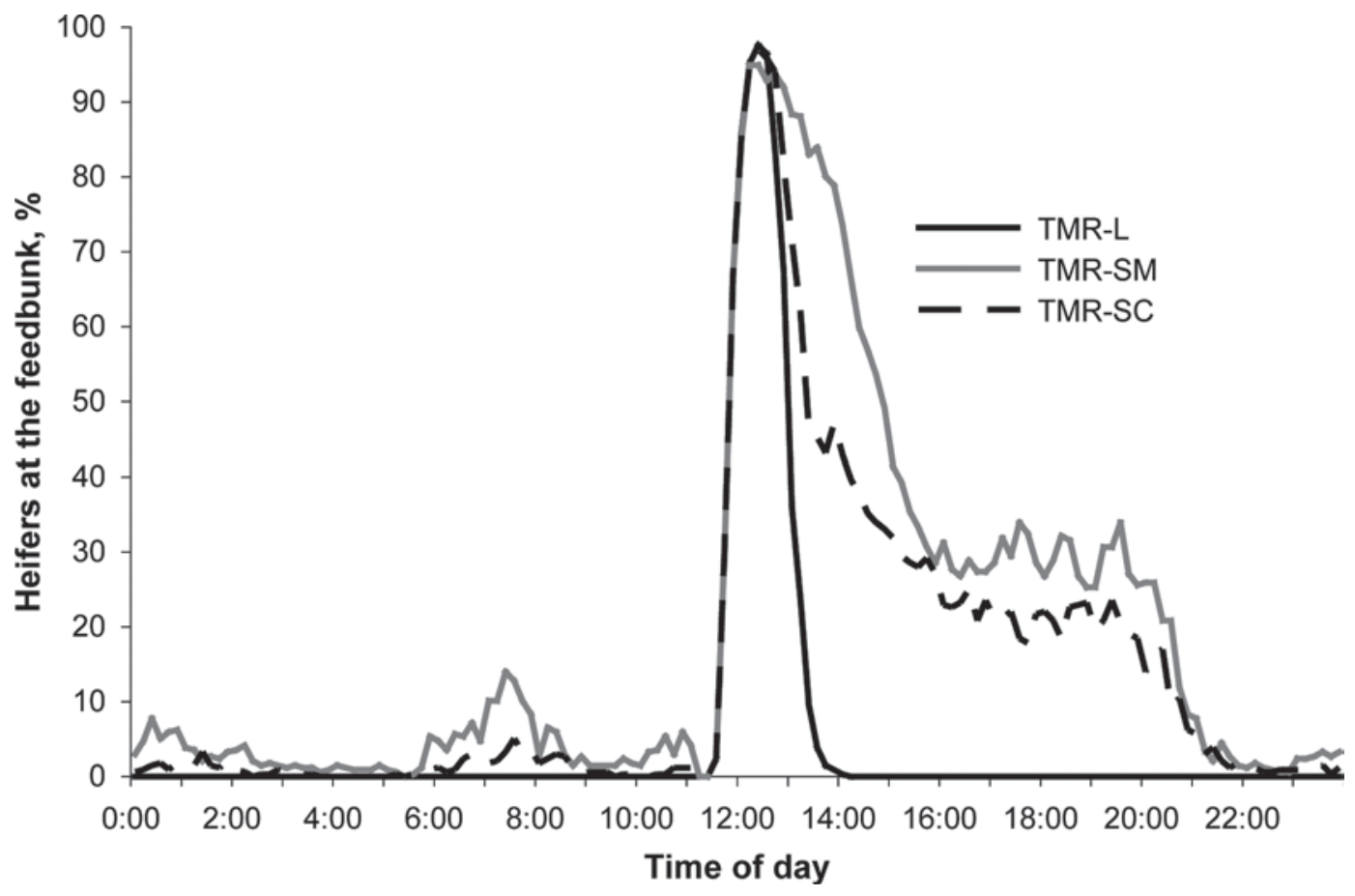

Figure 1. Percentage of heifers present at the feed bunk over a 24-h period (percentage for each 10-min interval during the day) for 3 treatments: (1) TMR in a limited amount (TMR-L), (2) TMR with straw (1.8 kg of DM/heifer per day) offered as a choice (TMR-SC), and (3) TMR with straw $(1.8 \mathrm{~kg}$ of DM/heifer per day) mixed in (TMR-SM). Data were averaged across $14 \mathrm{~d}$ for 6 pens (4 heifers/pen) per treatment.

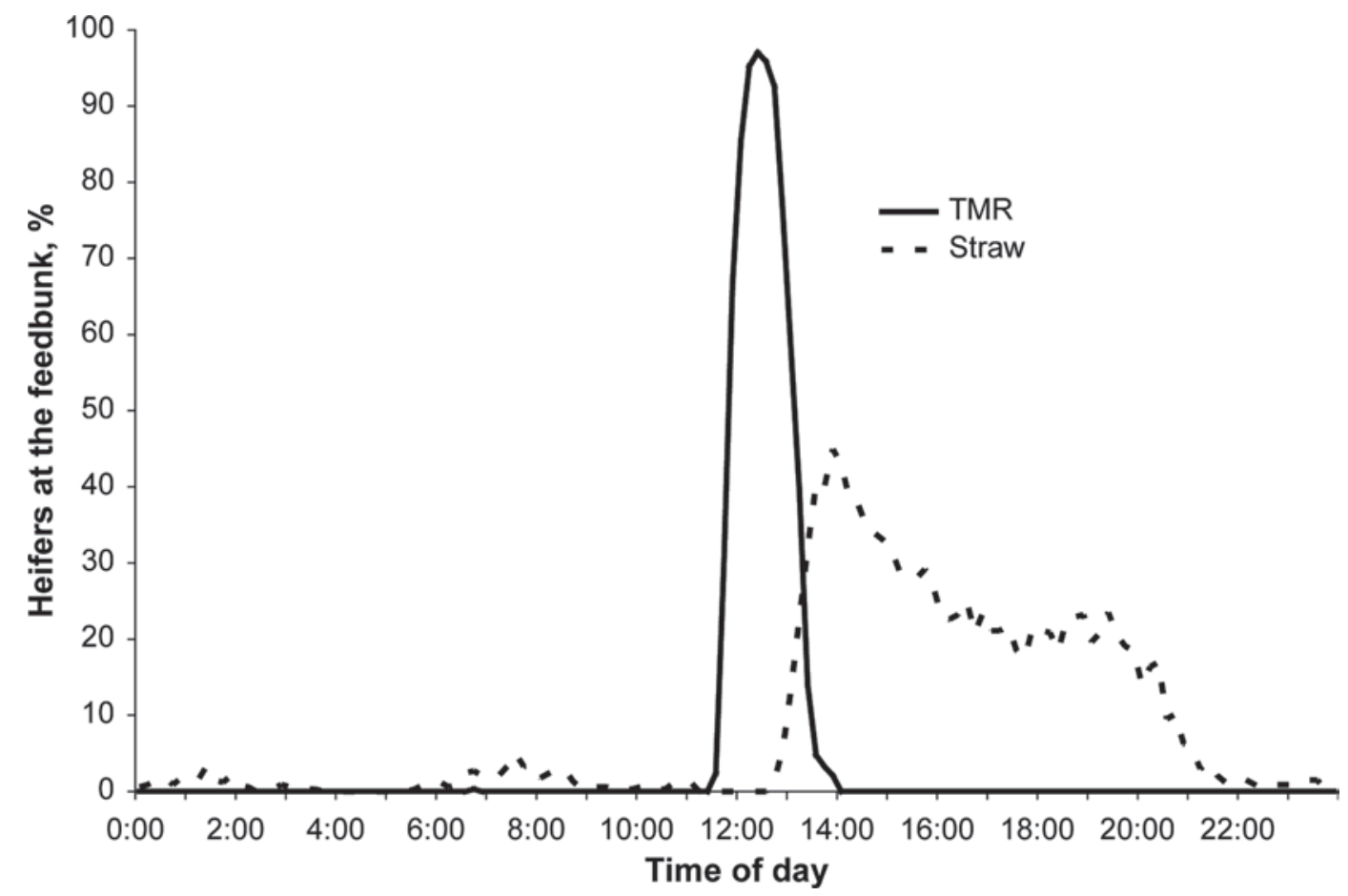

Figure 2. Percentage of heifers at the feed bunk over a 24-h period (percentage of each 10-min interval during the day) when consuming TMR and straw separately during the TMR-SC [TMR with straw (1.8 kg of DM/heifer per day) offered as a choice] treatment. Data were averaged across $14 \mathrm{~d}$ for 6 pens (4 heifers/pen). 
Table 5. Effect of treatment rations on nutrient and energy intakes and growth of growing dairy heifers ${ }^{1}$

\begin{tabular}{|c|c|c|c|c|c|}
\hline \multirow[b]{2}{*}{ Item } & \multicolumn{3}{|c|}{ Treatment $^{2}$} & \multirow[b]{2}{*}{$\mathrm{SE}$} & \multirow[b]{2}{*}{$P$-value } \\
\hline & TMR-L & TMR-SC & TMR-SM & & \\
\hline \multicolumn{6}{|l|}{ Nutrient intake } \\
\hline DMI, kg/d & $5.7^{\mathrm{a}}$ & $7.3^{\mathrm{b}}$ & $7.5^{\mathrm{c}}$ & 0.01 & $<0.001$ \\
\hline $\mathrm{ADF}, \mathrm{kg} / \mathrm{d}$ & $1.1^{\mathrm{a}}$ & $2.1^{\mathrm{b}}$ & $2.3^{\mathrm{c}}$ & 0.02 & $<0.001$ \\
\hline $\mathrm{NDF}, \mathrm{kg} / \mathrm{d}$ & $1.6^{\mathrm{a}}$ & $2.9^{\mathrm{b}}$ & $3.2^{\mathrm{c}}$ & 0.01 & $<0.001$ \\
\hline $\mathrm{peNDF},{ }^{3} \mathrm{~kg} / \mathrm{d}$ & $0.8^{\mathrm{a}}$ & $2.0^{\mathrm{b}}$ & $1.9^{\mathrm{c}}$ & 0.006 & $<0.001$ \\
\hline \multicolumn{6}{|l|}{ Energy intake } \\
\hline $\mathrm{TDN},{ }^{4} \mathrm{~kg} / \mathrm{d}$ & $4.1^{\mathrm{a}}$ & $4.9^{\mathrm{b}}$ & $4.7^{\mathrm{c}}$ & 0.008 & $<0.001$ \\
\hline $\mathrm{NE}_{\mathrm{G}}, \mathrm{Mcal} / \mathrm{d}$ & $6.2^{\mathrm{ab}}$ & $6.3^{\mathrm{b}}$ & $6.1^{\mathrm{a}}$ & 0.05 & 0.04 \\
\hline $\mathrm{NE}_{\mathrm{M}}, \mathrm{Mcal} / \mathrm{d}$ & $9.7^{\mathrm{a}}$ & $10.1^{\mathrm{ab}}$ & $10.5^{\mathrm{b}}$ & 0.1 & 0.02 \\
\hline \multicolumn{6}{|l|}{ Growth } \\
\hline $\mathrm{ADG}, \mathrm{kg} / \mathrm{d}$ & 0.9 & 0.9 & $0.8^{*}$ & 0.04 & 0.04 \\
\hline $\mathrm{ADGv},{ }^{5} \mathrm{~kg} / \mathrm{d}$ & 0.2 & 0.3 & 0.3 & 0.03 & 0.3 \\
\hline Feed efficiency (DMI/ADG) & $6.3^{\mathrm{a}}$ & $7.8^{\mathrm{b}}$ & $9.9^{\mathrm{c}}$ & 0.30 & 0.001 \\
\hline
\end{tabular}

${ }^{\mathrm{a}-\mathrm{c}}$ Values within rows with different superscript letters are significantly different $(P<0.05)$.

${ }^{1}$ DMI data are averaged over the last $14 \mathrm{~d}$ for each period treatment. Data for all other nutrients and energy intake are averaged over the last $7 \mathrm{~d}$ for each period treatment. Data for growth are averaged over the last 14 d of each period treatment.

${ }^{2} \mathrm{TMR}=21 \%$ corn silage, $19 \%$ alfalfa/grass silage, $45 \%$ high-moisture corn, and $15 \%$ protein supplement; TMR-L = limit-fed TMR; TMR-SC = TMR and straw offered on the side; TMR-SM = TMR and straw mixed within.

${ }^{3}$ peNDF $=$ measured as the NDF content of the treatment diets (DM basis) multiplied by the physical effectiveness factor.

${ }^{4} \mathrm{TDN}=$ total digestible nutrients.

${ }^{5} \mathrm{ADGv}=$ pen variance of average daily gain. ADGv was calculated by averaging, per pen, the absolute difference between individual heifer ADG and pen mean ADG.

*Value within row tended to differ from other values $(0.05<P \leq 0.1)$.

ments; however, the TMR-SC treatment had slightly higher levels than the TMR-SM treatment. The $\mathrm{NE}_{\mathrm{M}}$ levels differed between the TMR-L, which had the lowest level, and the TMR-SM treatment, which had the highest.

Heifer ADG tended to be lower for TMR-SM treatment compared with the TMR-SC and the TMR-L treatment $(P=0.06$, Table 5$)$. There was, however, no difference in the within-pen variation in growth. Feed efficiency differed among treatments, being the most improved on the TMR-L treatment and poorest on the TMR-SM treatment.

\section{DISCUSSION}

Limit feeding replacement dairy heifers has been demonstrated to have nutritional, environmental, and economical benefits. However, behavioral effects are associated with this feeding strategy that pose a concern for these animals. This study was designed to determine whether the addition of a low-nutritive feedstuff (wheat straw) to a limit-fed ration is able to alleviate these behavioral concerns without significantly affecting growth and feed efficiency. The 3 treatments all consisted of the same base ration fed in a limited amount corresponding to the TMR-L treatment. For the TMR-SC and TMR-SM treatments, $30 \%$ of DMI or $1.8 \mathrm{~kg}$ of $\mathrm{DM} /$ heifer per day of wheat straw was provided with the base ration. For the TMR-SM treatment, the straw was mixed directly into the base ration, changing the composition and particle size of the ration. The TMRSM ration had a greater percentage of $\mathrm{DM}, \mathrm{ADF}$, and $\mathrm{NDF}$ and a lesser percentage of $\mathrm{CP}, \mathrm{NFC}$, and $\mathrm{OM}$. The TMR-SM ration was still, however, formulated for a nonbred replacement Holstein heifer to maintain 0.9 $\mathrm{kg} / \mathrm{d}$ of growth (NRC, 2001). The addition of straw to the base ration also changed the particle size distribution of the ration, with more DM retained on the top screen, which were the long particles, and a decrease in DM on the medium, short, and fine screens.

As expected, $100 \%$ feed bunk attendance was observed for the TMR-L treatment for just over an hour after the daily provision of fresh feed; all of the feed was consumed in a period of $72.9 \mathrm{~min} / \mathrm{d}$. This is similar to results reported by Hoffman et al. (2007), where heifers that were limit-fed at a rate of $80 \%$ of ad libitum consumed all of their feed in $72 \mathrm{~min} / \mathrm{d}$. The consumption pattern and feeding time of the base TMR for heifers while on the TMR-SC treatment was similar to that when they were on the TMR-L treatment. However, these heifers almost immediately switched to consuming straw once the base TMR was finished (Figure 2). 
Heifers on the TMR-SC treatment spent just over 2 $\mathrm{h} / \mathrm{d}$ consuming the straw, resulting a total daily feeding time of just less than $3.5 \mathrm{~h}$. Heifers on the TMR-SM treatment had the longest peak in feeding activity following feed delivery and total daily feeding time (4.8 $\mathrm{h} / \mathrm{d}$ ). The feeding times and distribution of that time observed on the TMR-SC and TMR-SM treatment are thus more typical for ad libitum-fed replacement heifers, which typically have been reported to feed for 3 to $5 \mathrm{~h}$ per day, with that time spread throughout the day (Greter et al., 2008; DeVries and von Keyserlingk, 2009a). Therefore, in support of our hypothesis, the addition of straw to the limit-fed ration increased feeding time and the distribution of that time, thus allowing for a more natural feeding behavior pattern for these heifers.

Evidence suggests that satiety in cattle is linked not only to the amount of feed consumed, but also to the duration of consumption of that feed. When cattle do not spend much time consuming (orally manipulating) their feed, the potential exists for negative behavioral effects to develop. Lindström and Redbo (2000) looked at the importance of oral manipulation of feed in Swedish Red and White lactating dairy cows whether the rumen was full or not. These researchers discovered that even though the heifers were imposed with a physically full rumen, cows would still manipulate their feed. Lindström and Redbo (2000) suggested that the act of feed manipulation contributes to the negative feedback loop to decrease the animals' motivation to feed. It can therefore be suggested that heifers that are limit fed are metabolically satisfied, but not behaviorally satisfied (Lindström and Redbo, 2000). In our study, the results suggest that with the addition of straw, the heifers had sufficient bulk and feeding time to decrease their feeding motivation, and were thus assumed to be satiated. Heifers that were on the TMR-L treatment spent a greater amount of time at the feed bunk when no feed was present (unrewarded time) compared with the 2 straw treatments. While on the TMR-L treatment, heifers visited the empty feed bunk nearly 20 $\mathrm{min} / \mathrm{d}$ more than on the TMR-SC heifers and over 30 $\mathrm{min} / \mathrm{d}$ more than the TMR-SM heifers. This finding is similar to that of De Paula Vieira et al. (2008), who demonstrated that calves that were limit-fed doubled their amount of unrewarded visits to a milk feeder compared with calves fed ad libitum. Those researchers concluded that frequent unrewarded visits can be used as an indication of hunger.

As expected, DMI was greater for the 2 treatments with the provision of straw along with the limit-fed base TMR. Despite consumption of a greater amount of nutrients on the TMR-SC treatment, ADG was similar between this treatment and the TMR-L treatment.
Similar to this result, Hoffman et al. (2007) observed no difference in ADG when comparing an ad libitum-fed ration to more nutrient-dense rations fed at 90 and $80 \%$ of ad libitum intake. Further, Zanton and Heinrichs (2007) compared the provision of a high-forage ration to a low-forage ration on the growth of prepubertal dairy heifers and found that ADG was not affected by either treatment, with heifers gaining approximately $0.8 \mathrm{~kg} / \mathrm{d}$. With the higher DMI and similar ADG, feed efficiency of the TMR-SC treatment was decreased by $19 \%$ compared with the TMR-L treatment. This decrease in feed efficiency is slightly less than that reported by Hoffman et al. (2007), who demonstrated a $23.7 \%$ improvement in feed efficiency for heifers provided with a limit-fed ration (at $90 \%$ ad libitum) compared with those fed ad libitum. In the present study, feed efficiency was decreased by $37 \%$ on the TMR-SM treatment compared with the TMR-L treatment. It is known that feeding rations with greater physically effective NDF will reduce total-tract digestibility (Yang and Beauchemin, 2006b) and thus reduce efficiency of feed use.

To determine how the treatments affected rumen conditions, rumination behavior was observed using a 1-min scan for $1 \mathrm{~h}$ in the fifth hour after feed delivery. A tendency was found for fewer heifers ruminating on the TMR-L compared with the TMR-SM treatment during that period. The premise for these observations of rumination was based on the findings of DeVries et al. (2009), who found that suboptimal rumen function (i.e., an acidosis event) could be detected by observing the percentage of cattle within a group ruminating over at least 48 individual minutes during a period of time when rumination is expected (i.e., not during a period of feeding activity). Unfortunately, for the present study, the diurnal feeding pattern (Figure 1) of the heifers shows that some heifers on both straw treatments were still feeding during this observation period. Given that heifers on the TMR-SC and TMR-SM treatments consumed over twice as much physically effective fiber during the course of a day, it could be predicted that they would show increased rumination behavior. Therefore, it is likely that more of a difference in rumination behavior may have been detected if rumination had been measured at a much later period in the day, such as the late-night or early-morning period when little feeding activity was occurring.

The feed efficiency observed for the ad libitum ration fed in the Hoffman et al. (2007) study was 12.8 ( $\mathrm{kg}$ of $\mathrm{DM} / \mathrm{kg}$ of gain); this is much higher than the 7.8 observed for the TMR-SC treatment and 9.9 observed for the TMR-SM treatment. This would suggest that even though providing straw decreased efficiency compared with the limit-fed TMR, its provision either alongside or mixed within a limit-fed TMR may improve feed 
efficiency over that which could be achieved with a traditional high-forage, ad libitum-fed ration. Along with improvements in efficiency, it is also possible to reduce feed costs with such a feeding strategy. Utilizing local, current prices (in Canadian dollars) for the feed components used in this study (Ontario Ministry of Agriculture Food and Rural Affairs, 2010), we calculated that the base limit-fed TMR would cost CAN $\$ 1.17 / \mathrm{kg}$ of gain per heifer. For the provision of straw alongside the TMR, as in the TMR-SC treatment, the cost per kilogram of gain would increase by CAN $\$ 0.17$. The cost of feeding such a ration, even with straw, would be less than the cost of $\mathrm{CAN} \$ 1.50 / \mathrm{kg}$ of gain calculated for a typical, high-forage heifer feeding program in Ontario, Canada (Rodenburg, 2000).

Lying time was similar across all 3 treatments despite the fact that on the TMR-L treatment heifers were spending at least $2 \mathrm{~h}$ less time feeding per day. This translated into heifers spending more time inactively standing when on the TMR-L treatment. This is similar to results reported by Hoffman et al. (2007), who found that inactive standing time increased with increased feed restriction. Standing for long periods of time while not eating has been associated with the risk of lameness in dairy cattle (Greenough and Vermunt, 1991). Subacute ruminal acidosis, due to the increased consumption of highly fermentable carbohydrates, also is a risk factor for lameness (Nocek, 1997). Thus, long standing times along with increased risk of subacute ruminal acidosis may increase the risk of lameness in limit-fed heifers. Due to our experimental design (individual exposure to multiple treatments in 28-d treatment periods), we were unable to look at the long-term development of hoof pathologies in this study. It is recommended that future studies evaluate the long-term effect of such inactive standing time on the development of hoof pathologies in limit-fed heifers.

Feed bunk competition (i.e., frequency of displacements) was lowest on the TMR-L treatment and highest for the TMR-SM treatment. During the period of peak feeding activity $(1.5 \mathrm{~h}$ immediately after feed delivery), the frequency of displacements on the TMR-SM treatment was almost double that of both the TMR-L and TMR-SC treatments. This suggests that on the TMR-SM treatment, heifers were more motivated to compete for the TMR that was mixed with the straw. During that period of peak feeding activity, when all the TMR was consumed in the TMR-L and TMR-SC treatments, a similar frequency of displacements occurred between those treatments. This is of interest as a different amount of feed bunk space was available for access to the TMR in these treatments. On the TMR-L treatment, there was $0.68 \mathrm{~m} /$ heifer of feed bunk space, whereas there was $0.34 \mathrm{~m} /$ heifer of TMR feed bunk space due to the straw in the other half of the feed bunk. The similar level of competition suggests that when the heifers were consuming the TMR portion of the ration, they were highly motivated to consume the feed rather than engaging in competitive behavior. It is likely that at lower levels of feed bunk space, this competition would increase. Longenbach et al. (1999) suggested that increased competition resulting from feed bunk space being less than $0.31 \mathrm{~m} /$ heifer may have contributed to the increased variation in growth they observed in limit-fed heifers. Given that sufficient space existed for all animals to feed simultaneously in our study, it is not surprising that we did not detect any difference in pen variance in ADG between treatments. Overall, based on these results, it can be suggested that feeding straw alongside a limit-fed TMR, as opposed to mixed in, may prevent high levels of competition by heifers for access to the TMR given there is adequate feed bunk space.

\section{CONCLUSIONS}

Limit feeding is a beneficial feeding strategy for replacement dairy heifers; this feeding strategy improves feed efficiency, decreases DMI, and allows for ADG to be controlled. This feeding strategy does, however, reduce feeding time and increases inactive standing time. With the provision of straw alongside a limit-fed ration, heifers are able to increase their feeding time (to a similar amount of time observed for heifers fed ad libitum), increase rumination, decrease inactive standing time, and maintain their ADG. The provision of straw did decrease feed efficiency, but not to the extent of that typically seen on a high-forage, ad libitum-fed ration. Therefore, it can be concluded that limit feeding dairy replacement heifers is beneficial from a nutritional standpoint; however, it is recommended to provide a low-nutritive feedstuff alongside a limit-fed ration so that heifers can satisfy their natural foraging behavior, thus improving the overall welfare of these animals.

\section{ACKNOWLEDGMENTS}

We thank the staff at the University of Guelph, Kemptville Campus, Dairy Education and Research Centre, especially M. Kea, C. Felton, S. Beckinsale, M. Bruce, and A. Greter. We also thank A. Schouten, of Schouten Dairy Farms (Richmond, Ontario, Canada), for providing the heifers used in this experiment. This project was funded through an Ontario Ministry of Agriculture, Food and Rural Affairs (OMAFRA)/University of Guelph Production Systems research grant. 
This project was also supported through contributions from the Canadian Foundation for Innovation (CFI) and the Ontario Research Fund.

\section{REFERENCES}

AOAC. 2000. Official Methods of Analysis. Vol. I. 17th ed. Association of Official Analytical Chemists International, Arlington, VA.

Canadian Council on Animal Care. 1993. Guide to the Care and Use of Experimental Animals. Vol. 1. E. D. Olfert, B. M. Cross, A. A. McWilliam, ed. CCAC, Ottawa, Canada.

Cook, N. B., T. B. Bennett, and K. V. Nordlund. 2004. Effect of free stall surface on daily activity patterns in dairy cows with relevance to lameness prevalence. J. Dairy Sci. 87:2912-2922.

D'Eath, R. B., B. J. Tolkamp, I. Kyriazakis, and A. B. Lawrence. 2009. 'Freedom from hunger' and preventing obesity: The animal welfare implications of reducing food quantity or quality. Anim. Behav. 77:275-288.

De Paula Vieira, A., V. Guesdon, A. M. de Passillé, M. A. G. von Keyserlingk, and D. M. Weary. 2008. Behavioural indicators of hunger in dairy calves . Appl. Anim. Behav. Sci. 109:180-189.

DeVries, T. J., K. A. Beauchemin, F. Dohme, and K. S. SchwartzkopfGenswein. 2009. Repeated ruminal acidosis challenges in lactating dairy cows at high and low risk for developing acidosis: Feeding, ruminating, and lying behavior. J. Dairy Sci. 92:5067-5078.

DeVries, T. J., and M. A. G. von Keyserlingk. 2009a. Short communication: Feeding method affects the feeding behavior of growing dairy heifers. J. Dairy Sci. 92:1161-1168.

DeVries, T. J., M. A. G. von Keyserlingk, and D. M. Weary. 2004. Effect of feeding space on the inter-cow distance, aggression, and feeding behavior of free-stall housed lactating dairy cows. J. Dairy Sci. 87:1432-1438.

Endres, M. I., T. J. DeVries, M. A. G. von Keyserlingk, and D. M. Weary. 2005. Effect of feed barrier design on the behavior of loosehoused lactating dairy cows. J. Dairy Sci. 88:2377-2380.

Greenough, P. R., and J. J. Vermunt. 1991. Evaluation of subclinical laminitis in a dairy herd and observations on associated nutritional and management factors. Vet. Rec. 128:11-17.

Greter, A. M., T. J. DeVries, and M. A. G. von Keyserlingk. 2008. Nutrient intake and feeding behavior of growing dairy heifers: effects of dietary dilution. J. Dairy Sci. 91:2786-2795.

Hafez, E. S. E., and M. F. Bouissou. 1975. The behaviour of cattle. Pages $203-245$ in The Behaviour of Domestic Animals. 3rd ed. E. S. E. Hafez, ed. Bailliere Tindall, London, UK.

Heinrichs, A. J. 1993. Raising dairy replacements to meet the needs of the 21st century. J. Dairy Sci. 76:3179-3187.

Hoffman, P. C. 2007. The potential to limit feed dairy replacement heifers. Pages 186-192 in Proc. 68th Minnesota Nutr. Conf., Minneapolis, MN. Minnesota Extension Service, St. Paul, MN.

Hoffman, P. C., C. R. Simson, and M. Wattiaux. 2007. Limit feeding of gravid Holstein heifers: Effect on growth, manure nutrient excretion, and subsequent early lactation performance. J. Dairy Sci. 90:946-954.

Kertz, A. F., and H. Chester-Jones. 2004. Guidelines for measuring and reporting calf and heifer experimental data. J. Dairy Sci. $87: 3577-3580$.

Kononoff, P. J., A. J. Heinrichs, and D. R. Buckmaster. 2003. Modification of Penn State forage and total mixed ration particle separator and the effects of moisture content on its measurements. J. Dairy Sci. 86:1858-1863.

Lascano, G. J., G. I. Zanton, F. X. Suarez-Mena, and A. J. Heinrichs. 2009. Effect of limit feeding high- and low-concentrate diets with Saccharomyces cerevisiae on digestibility and on dairy heifer growth and first-lactation performance. J. Dairy Sci. 92:5100-5110.

Ledgerwood, D. N., C. Winckler, and C. B. Tucker. 2010. Evaluation of data loggers, sampling intervals, and editing techniques for measuring the lying behavior of dairy cattle. J. Dairy Sci 93:5129-5139.

Leonardi, C., and L. E. Armentano. 2003. Effect of quantity, quality, and length of alfalfa hay on selective consumption by dairy cows. J. Dairy Sci. 86:557-564.

Lindström, T., and I. Redbo. 2000. Effect of feeding duration and rumen fill on behaviour in dairy cows. Appl. Anim. Behav. Sci. 70:83-97.

Longenbach, J. I., A. J. Heinrichs, and R. E. Graves. 1999. Feed bunk length requirements for Holstein dairy heifers. J. Dairy Sci. 82:99-109.

Moody, M. L., G. I. Zanton, J. M. Daubert, and A. J. Heinrichs. 2007. Nutrient utilization of differing forage-to-concentrate ratios by growing Holstein heifers. J. Dairy Sci. 90:5580-5586.

Morris, T. R. 1999. Experimental Design and Analysis in Animal Sciences. CABI Publishing, New York, NY.

National Research Council. 2001. Nutrient Requirements for Dairy Cattle. Natl. Acad. Sci. Washington, DC.

Nocek, J. E. 1997. Bovine acidosis: Implications on laminitis. J. Dairy Sci. 80:1005-1028.

Ontario Ministry of Agriculture Food and Rural Affairs. 2010. Accessed July 14, 2010. http://www.omafra.gov.on.ca/english/index. html.

Quaiffe, T. 2002. Don't blame the big guys for higher heifer prices. Dairy Herd Manag. January:26-28.

Redbo, I., M. Emanuelson, K. Lundberg, and N. Oredsson. 1996. Feeding level and oral stereotypies in dairy cows. Anim. Sci. 62:199 206.

Redbo, I., and A. Nordblad. 1997. Stereotypies in heifers are affected by feeding regime. Appl. Anim. Behav. Sci. 53:193-202.

Rodenburg, J. 2000 Current status of heifer raising in Ontario. Accessed July 20, 2010. http://www.omafra.gov.on.ca/english/livestock/dairy/facts/info_raising.htm.

SAS Institute. 2003. User's Guide: Statistics. Version 9.1.3 ed. SAS Institute Inc., Cary, NC.

Savory, C. J., K. Maros, and S. M. Rutter. 1993. Assessment of hunger in growing broiler breeders in relation to a commercial restricted feeding program. Anim. Welf. 2:131-152.

Spoolder, H. A. M., J. A. Burbidge, S. A. Edwards, and P. H. Simmins. 1995. Provision of straw as a foraging substrate reduces the development of excessive chain and bar manipulation in food restricted sows. Appl. Anim. Behav. Sci. 43:249-262.

Stanton, A. L., D. F. Kelton, S. J. LeBlanc, S. T. Millman, J. Wormuth, R. T. Dingwell, and K. E. Leslie. 2010. The effect of treatment with long-acting antibiotic at postweaning movement on respiratory disease and on growth in commercial dairy calves. J. Dairy Sci. 93:574-581.

Van Soest, P. J., J. B. Robertson, and B. A. Lewis. 1991. Methods for dietary fiber, neutral detergent fiber and nonstarch polysaccharide in relation to animal nutrition. J. Dairy Sci. 74:3583-3597.

Vanegas, J., M. Overton, S. L. Berry, and W. M. Sischo. 2006. Effect of rubber flooring on claw health in lactating dairy cows housed in free-stall barns. J. Dairy Sci. 89:4251-4258.

Whittaker, X.. H. A. M. Spoolder, S. A. Edwards, A. B. Lawrence, and S. Corning. 1998. The influence of dietary fibre and the provision of straw on the development of stereotypic behaviour in food restricted pregnant sows. Appl. Anim. Behav. Sci. 61:89-102.

Yang, W. Z., and K. A. Beauchemin. 2006a. Physically effective fiber Method of determination and effects on chewing, ruminal acidosis, and digestion by dairy cows. J. Dairy Sci. 89:2618-2633.

Yang, W. Z., and K. A. Beauchemin. 2006b. Increasing the physically effective fiber content of dairy cow diets may lower efficiency of feed use. J. Dairy Sci. 89:2694-2704.

Zanton, G. I., and A. J. Heinrichs. 2007. The effects of controlled feeding of a high-forage or high-concentrate ration on heifer growth and first-lactation milk production. J. Dairy Sci. 90:3388-3396. 